\title{
Los desafíos de la Ley Nacional de Ejecución Penal en México
}

\author{
Gerardo HERNÁNDEZ* \\ Reyna MONDRAGÓN ESQUIVEL ${ }^{* *}$
}

\begin{abstract}
SUMARIO: Introducción. II. La Ley Nacional de Ejecución Penal y el complejo proceso de implementación de políticas en México. III. La reinserción social entre la fragmentación institucional y la retórica gubernamental. IV. Conclusiones. V. Bibliografia.
\end{abstract}

\section{INTRODUCCIÓN}

En el contexto de la política de seguridad del gobierno mexicano durante las dos recientes administraciones federales (2006-2012 y 2012-2018) se han realizado una serie de cambios institucionales que han buscado robustecer al Estado para hacer frente al flagelo de la inseguridad y el crimen organizado. Una de las reformas más significativas fue la del sistema de justicia penal en 2008, en la cual se pasó de un sistema inquisitivo a uno acusatorio. El efecto de este cambio institucional fue la gradual despresurización del sistema penitenciario, el cual entre 2006 y 2012 aumentó su población de 210,000 personas privadas de su libertad a 239,000, es decir,

* Investigador en el Instituto de Investigaciones Sociales de la Universidad Autónoma de Baja California, campus Mexicali; colaborador del Cuerpo Académico Estudios Sociales y Jurídicos, Derechos Humanos y Seguridad Pública (ghernandez48@uabc.edu.mx).

Maestra en Estudios Sociales y licenciada en Ciencia Política por la Universidad Autónoma Metropolitana; directora de Asuntos Internacionales para la Prevención Social; subsecretaría de Prevención y Participación Ciudadana, Secretaría de Gobernación (reynamondragon.es@gmail.com). 
un aumento de 28,949 internos. ${ }^{1}$ No obstante, como se menciona, estas cifras comenzaron a disminuir entre 2012 y 2016 - de acuerdo con la información actual disponible — de 239,000 reclusos a 212,000 personas privadas de la libertad. ${ }^{2}$

Esta disminución de la población privada de su libertad, por un lado, cumplía con uno de los objetivos del cambio institucional de 2008, y por otro, centró la discusión en otro de los problemas pendientes en la agenda pública, es decir, en el proceso de reinserción social que el Estado debe otorgar a las personas privadas de su libertad, en el momento en que regresan a la sociedad. Ante este panorama, en junio de 2011, la administración federal (2006-2012) reformó la Constitución Política (artículo 18) para que se elevara a rango constitucional el respeto de los derechos humanos en el sistema penitenciario. ${ }^{3}$ Asimismo, en 2016 —durante la administración federal 2012-2018 — se aprobó la Ley Nacional de Ejecución Penal (LNEP), la cual entró en vigor, parcialmente, en junio de 2016 y que tiene como objetivo establecer las normas que deben de observarse durante el internamiento por prisión preventiva, en la ejecución de penas y en las medidas de seguridad impuestas como consecuencia de una resolución judicial; determinar los procedimientos para resolver las controversias que surjan con motivo de la ejecución penal, y regular los medios para lograr la reinserción social.

Ante esto, no se puede obviar el avance que representa la creación de la LNEP, pero también los grandes retos que como política pública enfrenta dentro del sistema de justicia penal en México. Los desafíos implican no sólo el trabajo coordinado entre niveles de gobierno y entre instituciones locales, sino también dimensionar el problema que representan los centros de readaptación social en cada una de las entidades federativas de México. Cada uno de ellos, tanto federales como estatales, conforma un microcosmos con particularidades, en las que se conjugan las capacidades adminis-

1 Comisión Nacional de Seguridad, Cuaderno mensual de información estadística penitenciaria nacional, México, Órgano Administrativo Desconcentrado Prevención y Readaptación Social, 2013.

2 Encuesta Nacional de Población Privada de la Libertad, México, Instituto Nacional de Estadística y Geografía, 1993, p. 9.

3 Presidencia de la República, "Reforma constitucional en materia de derechos humanos", disponible en: http://calderon.presidencia.gob.mx/2011/06/promulgacion-de-lareforma-constitucional-en-materia-de-derechos-humanos (fecha de consulta: 10 de enero de 2018). 
trativas, operativas, económicas y políticas que determinan el rumbo de la reinserción social de los individuos privados de la libertad.

Por tal motivo, en el presente artículo se cuestiona lo siguiente: ¿cuáles son los principales obstáculos a los que se enfrenta como política pública la LNEP ante su instrumentación en las entidades federativas? Como hipótesis se plantea que los principales retos de la LNEP se encuentran en la capacidad que deberá tener el gobierno federal para coordinar, dirigir y evaluar los esfuerzos que realizan los gobiernos estatales en la tarea de implementación de la política pública, sobre todo porque la implementación muestra, por un lado, la fragmentación institucional del Estado para implementar políticas y, por otro, la retórica gubernamental de que los individuos privados de la libertad por el simple hecho de ser sometidos al proceso de reinserción social estarán en corresponsabilidad con la idea de orden y paz que conduce al Estado.

El trabajo se divide en dos secciones y un apartado final. En la primera se analiza normativamente la LNEP y se plantea el complejo proceso de implementación de la política pública. En la segunda parte se argumenta cómo la fragmentación institucional y la retórica gubernamental de la corresponsabilidad del individuo con el Estado limitan el alcance de la LNEP. Este apartado se apoya de los referentes teóricos de las políticas públicas y de entrevistas a especialistas en materia de reinserción social, así como a un director de un Centro de Reinserción Social (Cereso) en el estado de Quintana Roo. En la última sección se presentan las conclusiones. La investigación se apoya en los referentes teóricos de las políticas públicas.

\section{LA Ley Nacional de EJeCución PENAL Y EL COMPLEJO PROCESO DE IMPLEMENTACIÓN DE POLÍTICAS EN MÉXICO}

En México, la justificación constitucional de la cárcel ha ido cambiando a medida de que en el país los problemas de violencia e inseguridad se han posicionado con mayor urgencia en la agenda pública. Por ejemplo, entre 1917 y 1965, el objetivo fue lograr la "regeneración" de la persona que delinque. En 1971 fue publicada la Ley que Establece las Normas Mínimas sobre Readaptación Social de Sentenciados (LNMRSS), bajo la cual funcionaría el sistema penal en México hasta que en 2008 se dio el cambio institucional que creó la Ley Nacional de Ejecución Penal (LNEP) en 2016. En este periodo se pasó de hablar normativamente de "readaptación social del delincuente" a "reinserción social del sentenciado". No obstante, los 
avances normativos en materia penal no han significado una mejora en la práctica, y de manera particular se reflejan dos panoramas: el primero se presenta en los penales federales, donde el Estado pareciera tener mayor control, y el segundo, a nivel entidades federativas, donde la atomización de los problemas penitenciarios ha incrementado.

En julio de 2016, la población que estaba privada de la libertad se estimó en 233,469 internos tanto del fuero común como del fuero federal. Lo anterior representó una sobrepoblación de 24,221 internos. ${ }^{4}$ De acuerdo con el Diagnóstico Nacional de Supervisión Penitenciaria 2016, se registraron 1,538 incidentes violentos; de éstos, 1,250 ocurrieron en centros estatales y 288 se presentaron en centros federales. Los acontecimientos de mayor incidencia son riñas, desórdenes, homicidios, abusos, suicidios y motines. A este panorama se le suman los problemas de déficit de custodios, como en el caso de Quintana Roo, donde en 2014 se contabilizó - cifras que en 2016 empeoraron - un custodio por cada 19.83 internos; Chiapas, con un custodio por cada 19.37 internos, y Chihuahua, con un custodio por cada 19.21 internos. ${ }^{5}$ La consecuencia de lo anterior ha sido la pérdida del control de las cárceles, autogobiernos y fugas masivas en varios estados de la República (Veracruz, Zacatecas, Nuevo León, Tamaulipas, Durango, Sinaloa y Jalisco). ${ }^{6}$ Las situaciones descritas evidencian un problema que

4 Secretaría de Gobernación, Bases del Programa Nacional para la Prevención Social de la Violencia y Delincuencia e Instalación de la Comisión Intersecretarial, México, Secretaría de Gobernación, 2013.

5 Muedano, Marcos, "Registran cárceles déficit de custodios", El Universal, México, 2012, disponible en: http://www.eluniversal.com.mx/primera/40382.html (fecha de consulta: 10 de enero de 2018). También es necesario señalar que la ONU recomienda que por cada 10 reos debe haber un custodio.

6 En 2010 se fugaron del penal estatal de Nuevo Laredo, Tamaulipas, 141 presos - 83 del fuero común y 58 del fuero federal- En Durango, los internos del penal tenían permiso de la directora del Cereso 2 de Gómez Palacio, Margarita Rojas, para salir a cometer delitos y posteriormente regresar. El 16 de marzo de 2017 se fugó del penal de Culiacán, Sinaloa, Juan José Esparragoza Monzón, encarcelado por delitos del fuero federal. El 9 de mayo de 2017 se dio a conocer una fiesta al interior del penal estatal de Puente Grande, Jalisco, en la que se festejaba el cumpleaños de José Gutiérrez Valencia, "Don Chelo", miembro del Cártel Jalisco Nueva Generación. En este sentido, véanse Galindo, Pedro, "En Durango también se fugan”, El Siglo de Torreón, Durango, 2015, disponible en: https://www.elsiglodedurango.com.mx/noticia/603949.en-durango-tambien-se-fugan. html (fecha de consulta: 15 de enero de 2018); Bustamante, Jesús, "Tenía dos meses preso y se fuga hijo de El Azul; Sinaloa pide ayuda federal", Excélsior, Culiacán (Sinaloa), 2017, disponible en: http://www.excelsior.com.mx/nacional/2017/03/17/1152456 (fecha de consulta: 30 de enero de 2018); "Escapan 141 presos del penal de Nuevo Laredo", La 
no fue atendido por un largo tiempo - a pesar de que a nivel normativo se avanzó- y que ha evitado el cumplimiento del fin del sistema penitenciario: la reinserción social.

En este sentido, la LNEP fue creada para contrarrestar el grave problema de los centros penitenciarios, a través de privilegiar la base de principios, garantías y derechos consagrados en la Constitución, así como en tratados internacionales de los que el Estado mexicano sea parte. En el siguiente cuadro se pueden apreciar los artículos más determinantes en materia de derechos de los reclusos y la forma en que la política penitenciaria pretende ser instrumentada. Se destacan los servicios médicos, los programas educativos y la finalidad e importancia del trabajo como medidas para la reinserción social.

\section{Cuadro 1. Ley Nacional de Ejecución Penal (2016)}

\begin{tabular}{|c|c|}
\hline $\begin{array}{c}\text { Artículo } 34 \\
\text { Atención médica }\end{array}$ & $\begin{array}{l}\text { La Autoridad Penitenciaria en coordinación con la Secretaría de Sa- } \\
\text { lud Federal o sus homólogas en las entidades federativas y de acuer- } \\
\text { do con el régimen interior y las condiciones de seguridad del Centro } \\
\text { deberán brindar la atención médica en los términos de la Ley Gene- } \\
\text { ral de Salud. } \\
\text { La Autoridad Penitenciaria, en coordinación con las instituciones } \\
\text { públicas del Sistema Nacional de Salud competentes, garantizarán } \\
\text { la permanente disponibilidad de medicamentos que correspondan al } \\
\text { cuadro básico de insumos para el primer nivel de atención médica, y } \\
\text { establecerán los procedimientos necesarios para proporcionar opor- } \\
\text { tunamente los servicios e insumos requeridos para otros niveles de } \\
\text { atención. }\end{array}$ \\
\hline $\begin{array}{c}\text { Artículo } 36 \\
\text { Mujeres privadas } \\
\text { de la libertad con } \\
\text { hijas o hijos }\end{array}$ & $\begin{array}{l}\text { Las mujeres privadas de la libertad embarazadas deberán contar con } \\
\text { atención médica obstétrico-ginecológica y pediátrica, durante el em- } \\
\text { barazo, el parto y el puerperio, el cual deberá realizarse en hospitales } \\
\text { o lugares específicos establecidos en el Centro Penitenciario cuando } \\
\text { cuenten con las instalaciones y el personal de salud especializado. }\end{array}$ \\
\hline $\begin{array}{c}\text { Artículo } 49 \\
\text { Previsión general }\end{array}$ & $\begin{array}{l}\text { Las personas sentenciadas podrán cumplir con la resolución ju- } \\
\text { dicial privativa de la libertad en los Centros Penitenciarios más } \\
\text { cercanos a su domicilio. Esta disposición no aplica en el caso de } \\
\text { delincuencia organizada y respecto de otras personas privadas de la } \\
\text { libertad que requieran medidas especiales de seguridad en los térmi- } \\
\text { nos del penúltimo párrafo del artículo } 18 \text { Constitucional. }\end{array}$ \\
\hline
\end{tabular}

Jornada, México, 2010, disponible en: http://www.jornada.unam.mx/2010/12/18/politica/ 002n1pol (fecha de consulta: 20 de enero de 2018); “«Narcoreventón» del cártel Jalisco... en «su» presidio", Milenio, México, 2017, disponible en: http://www.milenio.com/po licia/narco-reventon-fiesta-cartel_jalisco-presidio-penal-puente_grande-don_chelo-mile nio_0_953304665.html (fecha de consulta: 15 de enero de 2018). 
Artículo 51

Traslados

involuntarios

Artículo 75

Examen médico

de ingreso

Artículo 86

Programas

educativos

El traslado involuntario de las personas privadas de la libertad procesadas o sentenciadas deberá ser autorizado previamente en audiencia pública por el Juez de Control o de Ejecución, en su caso. Dicha resolución podrá ser impugnada a través del recurso de apelación.

Artículo 91 El trabajo constituye uno de los ejes de la reinserción social de las Naturaleza y finalidad del trabajo A toda persona privada de su libertad recluida en un Centro se le practicará un examen psicofísico a su ingreso, para determinar el tratamiento de primer nivel que requiera.

La Autoridad Penitenciaria deberá celebrar convenios de colaboración con Instituciones públicas y privadas de carácter nacional e internacional en materia educativa para ampliar la oferta educativa y su calidad. personas privadas de la libertad y tiene como propósito prepararlas para su integración o reintegración al mercado laboral una vez obtenida su libertad.

FUENTE: Elaboración propia con datos de la Ley Nacional de Ejecución Penal (2016).

De igual manera, en la LNEP se estipularon los beneficios preliberacionales y las sanciones no privativas de la libertad. Dentro lo anterior, se encuentra la libertad condicionada, la libertad anticipada, la sustitución y suspensión temporal de las penas, los permisos humanitarios, la preliberación por criterios de política penitenciaria, la justicia terapéutica, así como las sanciones y medidas penales no privativas de la libertad.

No obstante, los cambios institucionales parten de una realidad que evidencia el distanciamiento que existe entre las reglas escritas y la implementación de la política pública en el sistema penitenciario. La asimetría señalada no significa que el sistema nacional penitenciario se encuentre en peores condiciones que en el pasado.

De hecho, y de acuerdo con el Órgano Administrativo Desconcentrado Prevención y Readaptación Social (OADPRS), con el nuevo sistema de justicia penal, en el periodo de 2012-2016 disminuyeron el número de presos a nivel nacional. En 2012 se registraron 239,089 internos y en 2016 la cifra se ubicó en 233,469 reclusos. Ésta fue una disminución que pareciera no ser significativa $-5,620$ internos_2016 el decremento fue de 21,236 reclusos. ${ }^{7}$ En este mismo sentido, a nivel federal los Centros Federales de Readaptación Social (Ceferesos) tienen contabilizados avances en el Programa de libertad anticipada y patronato

7 Comisión Nacional de Seguridad, Cuaderno mensual de información estadística penitenciaria nacional, México, Órgano Administrativo Desconcentrado Prevención y Readaptación Social, 2016. 
para liberados; sin embargo, no se cuenta con información estadística que refleje el seguimiento por parte de las entidades federativas y de los Centros Estatales de Reinserción Social (Ceresos) bajo su jurisdicción para conocer si esas personas lograron reinsertarse a la vida laboral y productiva. ${ }^{8}$

Si bien es cierto que esto muestra una falta de cooperación entre órdenes de gobierno, también refleja una falta de coordinación del Estado y sus instituciones. Aunado a lo anterior, se encuentra la paradoja de que, mientras se aplica una serie de medidas para despresurizar los centros penitenciarios, los índices de criminalidad están en aumento. Una explicación a este tema se encuentra en que, si bien los mecanismos alternos de solución de controversias y la suspensión condicional del proceso son una aportación novedosa y de carácter más humano, existe una falta en el seguimiento de las mismas. Esto se refiere a permitir a los imputados cumplir con su proceso en libertad, pero existe un seguimiento endeble del cumplimiento de las condicionantes impuestas. Esto se refleja necesariamente en la Encuesta Nacional de Victimización y Percepción sobre Seguridad Pública 2017 (Envipe), ${ }^{9}$ la cual mostró que durante 2016 hubo 31 millones de delitos y 24.2 millones de víctimas (Envipe, 2017). ${ }^{10}$ Con respecto a las cifras registradas en 2010, éstas indican que en ese año hubo 22,714,967 delitos y 17.84 millones de víctimas (Envipe, 2011). ${ }^{11}$

Así, uno de los retos es comprender de inicio a la reinserción social como un proceso dinámico en el que la persona regresa a la vida en libertad, al mismo tiempo que la sociedad facilita dicho proceso a través de "un conglomerado de instituciones públicas, privadas y sociedad civil". Este proceso debe iniciarse desde que la persona cometió un delito, y no únicamente cuando está a punto de obtener su libertad. De acuerdo con un estudio realizado por la Oficina de Naciones Unidas contra la Droga y el Delito (ONUDD), "no es poco común encontrar situaciones en las que las leyes y

8 Auditoría Superior de la Federación, Auditoría de desempeño del sistema nacional penitenciario, México, Auditoría Superior de la Federación, 2016, pp. 6-10.

9 La Envipe obtiene información a nivel nacional y estatal que permite realizar estimaciones de la prevalencia delictiva que afecta a los hogares en México, es decir, la incidencia delictiva y la cifra negra. Asimismo, busca obtener información sobre la percepción de la seguridad pública, así como el desempeño de las instituciones a cargo de la seguridad pública y la justicia.

10 Encuesta Nacional de Victimización y Percepción sobre Seguridad Pública 2016. Resultados, México, Instituto Nacional de Estadística y Geografía, 2017.

11 Encuesta Nacional de Victimización y Percepción sobre Seguridad Pública 2011. Resultados, México, Instituto Nacional de Estadística y Geografía, 2011. 
las políticas asumen que existen programas de reintegración en las prisiones y en la comunidad aún si, en la realidad, dichos programas apenas existen, son muy rudimentarios o son accesibles sólo para un porcentaje muy pequeño de delincuentes".

\section{LA REINSERCIÓN SOCIAL ENTRE LA FRAGMENTACIÓN INSTITUCIONAL Y LA RETÓRICA GUBERNAMENTAL}

El panorama anterior conlleva a cuestionar cuáles son los restos a los que se enfrenta la nueva LNEP y su tarea de garantizar los derechos humanos para lograr la reinserción social. Cabe señalar que, como toda política pública, la LNEP se enfrenta al proceso que puede derivar en el éxito o el fracaso en la implementación. Dentro del proceso señalado se identifican la "fragmentación institucional y la retórica del individuo en corresponsabilidad con el Estado".

\section{La fragmentación institucional}

Las políticas públicas que un gobierno implementa siempre están sujetas a la incertidumbre de la implementación, que a menudo terminan por no dar los resultados esperados, en el corto o mediano plazo. En México, por ejemplo, las políticas públicas contra la pobreza, a pesar de destinárseles una gran cantidad de recursos, no han logrado disminuir en el mediano plazo la tasa de pobreza. En 2014, el Consejo Nacional de Evaluación de la Política de Desarrollo Social (Coneval) informó que 46.2\% de personas se encuentran en condición de pobreza, lo cual representó 55.3 millones de personas, 2 millones más que en 2012. ${ }^{12}$

De igual manera, existen un gran número de políticas públicas que no terminan de reflejar lo que el diseño normativo estipuló. Sin embargo, la pregunta que recurrentemente se hace es ¿por qué fallan las políticas? Lo anterior se menciona debido a que la LNEP podría enfrentarse a una serie de complejidades que afectarían los objetivos trazados. En este sentido, es importante señalar que una política pública en estricto sentido es "el conjunto de actividades de las instituciones de Gobierno, actuando direc-

12 Consejo Nacional de Evaluación de la Política de Desarrollo Social, Informe de Evaluación de la Política de Desarrollo Social 2016. Resultados, México, Consejo Nacional de Evaluación de la Política de Desarrollo Social, 2016. 
tamente o a través de agentes, y que van dirigidos a tener una influencia determinada sobre la vida de los ciudadanos". ${ }^{13}$

De ahí que, cuando un problema escala a la agenda pública, se tengan que localizar datos y elaborar interpretaciones relevantes para plantear una mejora en la toma de decisiones de la política que atiende ese problema en particular o elaborar una nueva política pública. En este proceso de diseño de política pública, la participación ciudadana es importante, pues junto al gobierno deben definir los instrumentos y las acciones (de acuerdo con las demandas del problema) de la implementación. ${ }^{14}$ Es por eso que una política pública, generalmente, constituye la respuesta a una demanda social, aunque también puede ser la anticipación de las autoridades gubernamentales para atender y desactivar posibles problemas sociales que podrían detonar en el futuro de un modo más peligroso. Esto no quiere decir que a veces ellas mismas no representen dificultades que provoquen demandas y produzcan exigencias. ${ }^{15}$

En el caso del sistema penitenciario en México, la LNEP busca atender un problema que por mucho tiempo ha mermado el respeto a los derechos humanos y la eficacia de los programas de reinserción social en el sistema penitenciario. En este sentido, y como en todo ciclo de política pública, el proceso de implementación es fundamental para el éxito o el fracaso de los objetivos (véase cuadro 2). Esto se menciona debido a que es en la implementación donde entran en juego no solamente los responsables de llevarla a cabo, sino también quienes han de beneficiarse con ella $\mathrm{y}$, a su vez, los agentes que resultan afectados con los cambios. ${ }^{16}$

Cuadro 2

Ciclo de VIDA DE LAS POLíticas PÚBLICAS

Gestación

Diseño

Implementación

Evaluación de impacto

FUENTE: Elaboración propia con datos de Franco Corzo, J., Diseño de políticas públicas, México, IEXE, 2013, p. 146.

13 Pérez Sánchez, Margarita, "El estudio de las políticas públicas”, en Pérez Sánchez, Margarita (ed.), Análisis de políticas públicas, Universidad de Granada, 2005, p. 52.

14 Franco Corzo, J., Diseño de políticas públicas, México, IEXE, 2013, pp. 86 y 87.

15 Pasquino, Gianfranco, Nuevo curso de ciencia política, México, Fondo de Cultura Económica, 2011, p. 270.

16 Merino, Mauricio, Políticas públicas. Ensayo sobre la intervención del Estado en la solución de problemas públicos, México, Centro de Investigación y Docencia Económica, 2016, pp. 46 y 47. 
De forma adicional, la producción e implementación de las políticas es influida por lo fuerte que es un Estado y sus instituciones, así como de los intereses de los diferentes actores que intervengan. ${ }^{17}$ La diversidad de actores que participan en ella, de manera directa o indirecta, son gobierno; los tres poderes del Estado; los partidos políticos; las organizaciones defensoras de algún interés colectivo, público o no; las empresas y corporaciones empresariales; las ONGs (organizaciones de la sociedad civil); los expertos; los medios de comunicación; los individuos influyentes, y la opinión pública. ${ }^{18}$

Lo anterior es independientemente de que la autoridad sea quien decida qué política pública se instrumentará. Todo lo expuesto sirve para analizar los artículos transitorios de la LNEP, que plantean que deberá existir un trabajo coordinado entre agentes del gobierno para llevar a cabo la ejecución de las reglas. En el siguiente cuadro se puede ejemplificar el número de agentes que deberán intervenir en la implementación de la LNEP.

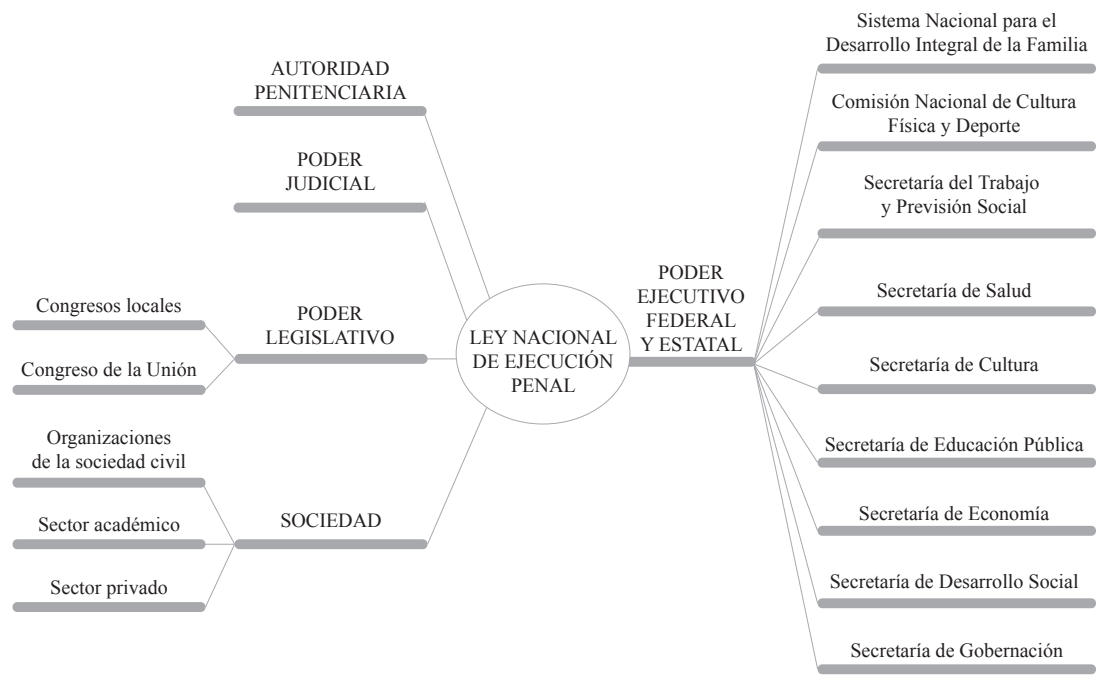

FUENTE: Elaboración propia.

17 Medellín Torres, Pedro, La politica de las politicas públicas: propuestas teórica y metodológica para el estudio de las políticas públicas en países de frágil institucionalidad, Santiago de Chile, CEPAL, 2004, pp. 5-56.

18 Real Dato, J., "Actores, ideas e instituciones en las políticas públicas”, en Pérez Sánchez, Margarita (ed.), Análisis de politicas públicas, Universidad de Granada, 2005, pp. 79-87. 
Identificados los agentes que intervendrán en el proceso de implementación, la política pública queda subordinada a las posibilidades que cada organización tiene para llevarla a cabo. ${ }^{19}$ En el caso de la LNEP, los gobiernos estatales (gobernadores, congresos locales, autoridades penitenciarias y Poder Legislativo), quedaron sujetos en los artículos cuarto y quinto transitorios.

\section{Cuarto...}

Las entidades federativas deberán adecuar su legislación a efecto de derogar las normas relativas a la remisión parcial de la pena, libertad preparatoria y sustitución de la pena durante la ejecución, en el ámbito de sus respectivas competencias. Las entidades federativas deberán legislar en sus códigos penales sobre las responsabilidades de los supervisores de libertad.

Quinto. En un plazo que no exceda de ciento ochenta días naturales después de publicado el presente Decreto, la Federación y las entidades federativas deberán publicar las reformas a sus leyes que resulten necesarias para la implementación de esta Ley... ${ }^{20}$

Sin embargo, es importante señalar que, a pesar de que normativamente se establece el camino que se debe seguir, esto no implica un camino terso y sin complejidades. Lo anterior se menciona debido a que, dentro del entramado institucional y organizacional, los comportamientos, los valores, las costumbres y los intereses personales juegan un papel fundamental. Esto quiere decir, que inevitablemente se presenta un doble juego o una interacción entre instituciones formales e informales. Las primeras entendidas como "las reglas del juego de una sociedad o, más formalmente, son las limitaciones ideadas por el hombre que dan forma a la interacción humana. Por consiguiente, estructuran incentivos en el intercambio humano, sea político, social o económico —el sistema electoral y las constituciones, entre otras — ". ${ }^{21}$

Las segundas son producto de usos y costumbres de las sociedades; se encuentran en las esferas pública y privada — por ejemplo, el clientelismo y la corrupción—. ${ }^{22}$ En este punto, es necesario señalar que un problema

19 Merino, José, op. cit., p. 3.

20 Artículos cuarto y quinto transitorios, Ley Nacional de Ejecución Penal (LNEP).

21 North, Douglas, Instituciones, cambio institucional y desempeño económico, México, Fondo de Cultura Económica, 1993, pp. 13 y 14.

22 Ayala Espino, José, Instituciones y economía, una introducción al neoinstitucionalismo económico, México, Fondo de Cultura Económica, 2011, p. 67. 
en el que recurrentemente se cae es en asumir que todas las organizaciones o actores responsables de la implementación tienen la voluntad y la capacidad institucional, organizacional y financiera para hacer frente a los compromisos que imponen las reglas formales.

Por tal motivo, y como plantea Merino, si una organización tiene recursos escasos y está obligada por el marco normativo a realizar procedimientos derivados de políticas tan diversas como complejas, no podrá cumplir sus propósitos o, al menos, no lo hará con la misma eficacia. ${ }^{23}$ Es por eso, y retomando lo antes señalado, que es importante no perder de vista cómo se comportan las instituciones informales en el proceso de implementación. Esto se menciona porque no sólo se trata de contar o no con recursos, sino también de los diversos intereses que cada uno de los agentes involucrados posee.

En este punto, se observa que uno de los principales retos de la LNEP es la coordinación y vinculación entre los sectores público, privado y social, además de atender y combatir los vicios organizacionales - corrupción, falta de capacitación y de profesionalización - que se heredan. En este mismo sentido, la especialista en alternativas al encarcelamiento y reinserción social, Ariadna Camacho Contreras, plantea:

El mayor reto es voluntad política para los operadores del Sistema Penitenciario para realizar los cambios que se estipulan en la Ley, el segundo más importante será la cooperación de las Autoridades Corresponsables para el desarrollo de programas y asignación de recursos para las personas en reclusión y el tercero será la capacitación y profesionalización de los funcionarios que trabajan en los centros penitenciarios aunado a mayores prestaciones para ellos, para evitar la corrupción. ${ }^{24}$

De igual manera, se pueden asumir dos posturas: a) es cierto que las reglas informales tienen un peso determinante, así como los intereses de grupos colectivos — en los que se incluye el gobierno federal—, los cuales buscan rentabilidad en la implementación, ya sea retrasando (política) o manejando a discrecionalidad (económica) los recursos presupuestales, y b) que este tipo de escenarios en la implementación de políticas tiene que ver con la "fragmentación institucional" en la que se encuentra el Estado

\footnotetext{
23 Merino, José, op. cit., pp. 2 y 3.

24 Entrevista realizada el 13 de junio de 2017, Ciudad de México.
} 
mexicano. Una política pública como la penitenciaria necesariamente involucra o refleja el grado de control que posee el gobernante sobre el aparato estatal y la sociedad que gobierna. En los artículos sexto y séptimo transitorios se señala que los gobiernos estatales serán quienes erogarán en sus programas presupuestarios lo que le corresponda de la implementación de la política pública:

\section{Sexto...}

Asimismo, las entidades federativas deberán realizar las previsiones y adecuaciones presupuestales necesarias para dar cumplimiento a las obligaciones establecidas en este Decreto.

Séptimo...

...las entidades federativas... deberán prever en sus programas la adecuada y correcta implementación, y deberán establecer dentro de los proyectos de presupuesto respectivos, las partidas necesarias para atender la ejecución de esos programas, las obras de infraestructura, la contratación de personal, la capacitación y todos los demás requerimientos necesarios para cumplir los objetivos de la presente Ley. ${ }^{25}$

Las disposiciones normativas se enfrentan al hecho de que esto exige tener capacidad financiera por parte de los principales involucrados - gobierno federal y gobiernos estatales- No obstante, en 2017, la Secretaría de Hacienda y Crédito Público (SHCP) solicitó al Congreso evitar o postergar la aprobación de leyes que en su puesta en marcha implicaran gastos extraordinarios. Esto involucró directamente a la LNEP, donde el gobierno federal necesitaba presupuestar 20,000 millones de pesos para su implementación. ${ }^{26}$

El panorama expuesto puede llevar a asumir que, si bien los cambios institucionales en materia de sistema penitenciario son avances cualitativos, éstos no necesariamente se pueden cuantificar al momento de analizar el proceso de implementación. Este escenario complejo — por la falta de interés, voluntad política o presupuesto - también lo reconoce la especialista en alternativas al encarcelamiento y reinserción social, Ariadna Camacho Contreras:

25 Artículos sexto y séptimo transitorios, LNEP.

26 Robles de la Rosa, Leticia y Rosas, Tania, "Sin dinero para nueva ley penal; austeridad posterga su aplicación”, Excélsior, México, 2017, disponible en: http://www.excelsior. com.mx/nacional/2017/05/16/1163716 (fecha de consulta: 5 de febrero de 2018). 
Los Centros Penitenciarios no han sido una prioridad en los temas de seguridad pública en México, en este sentido hay una falta de interés por parte de todos los operadores de hacer los cambios que se necesitan. Por otro lado tampoco se han asignado los recursos suficientes a este sector para poder hacer los cambios que se necesitan... Actualmente no se ha asignado un recurso para la instrumentación de esta política (LNEP), al parecer se apuesta por la asignación de recursos y programas de las autoridades corresponsables, en donde puedan sumar a las actividades del sistema penitenciario, sin embargo será fundamental asignar recursos para la capacitación y profesionalización en este sector así como para la creación de programas integrales de reinserción, la creación de la unidad de servicios postpenales y para dotar al sistema de todos los recursos humanos necesarios como médicos, pediatras, ginecológicos, criminólogos así como dotar a los internos de todos los insumos necesarios para garantizar sus derechos humanos... al parecer únicamente se hizo la reforma, se estableció que las autoridades corresponsables tenían que colaborar con sus programas y les impusieron la obligación de asignar presupuestos para este sector, sin embargo tampoco se evaluó la capacidad financiera de las Entidades Federativas. ${ }^{27}$

Lo anterior toma sentido si se analiza el Presupuesto de Egresos de la Federación 2016 (PEF), en el cual el rubro "Seguridad Pública" estipuló un presupuesto de 18,824.53 millones de pesos asignados para "Reclusión y readaptación social" (Ramo 04 Gobernación), teniendo una diferencia de $-1,277.53$ millones de pesos respecto al PEF de 2015, en el que se asignó a este mismo rubro 20,102.06 millones de pesos. ${ }^{28}$ La situación tampoco es distinta con respecto a los estados, debido a que 20 de las 32 entidades federativas, en un periodo de 15 años (2000-2015), han disminuido su recaudación fiscal (impuesto sobre la renta; impuesto al valor agregado, e impuesto especial sobre producción y servicios). ${ }^{29}$

El escenario anterior afecta de manera determinante el cumplimiento de mejoras en infraestructura en los centros penitenciarios estatales y, en ese mismo sentido, el poder mejorar las condiciones de los derechos humanos y programas para la reinserción social de los individuos. Un ejemplo claro

27 Entrevista realizada el 13 de junio de 2017, Ciudad de México.

28 Cámara de Diputados, El presupuesto público federal para la función seguridad pública, 2015-2016, México, Cámara de Diputados, LXIII Legislatura, 2016.

29 Patiño, Dainzú, "Entidades reducen su participación en la recaudación de impuestos", El Financiero, México, 2016, disponible en: http://www.elfinanciero.com.mx/econom ialestados-reducen-su-participacion-en-la-recaudacion-de-impuestos.html (fecha de consulta: 2 de marzo de 2018). 
de esta situación acontece en el Cereso de Quintana Roo, el cual en sus instalaciones tiene en promedio 41 reclusos por cada custodio - triplica la media nacional que es de $11-,{ }^{30}$ además de no contar con un equipo o consejo interdisciplinario íntegro, debido a que no se encuentra con espacios para su composición. Lo anterior es reconocido y argumentado por el director del Cereso de Chetumal, Quintana Roo:

Uno de los fallos que tienen los centros de reinserción social se encuentra en la integración del Consejo Técnico... un Consejo debe estar integrado por gente capacitada y especializada en el tema de reinserción... la falta de vocación interinstitucional y los fallos en el tema de reinserción social se debe a la carencia de espacios y formación de la gente que se encuentra laborando en cada dependencia... la falla es interna reflejado por el individuo ya puesto en libertad. El Consejo Técnico interdisciplinario no tiene una integración exacta y adecuada, no existe en este centro el área criminológica por falta de plazas o carencias dentro del sistema de seguridad pública y económica del gobierno estatal, el área por ahorita se encuentra inexistente ya que como se puede ver, como otro ejemplo, las áreas o el consejo está formado por aquellas personas que se integran como el personal de custodia u otras formas. Ahora dentro del sistema penal el Centro de Reinserción Social de Chetumal, se encuentra en un estado de responsabilidad moral debido a que el gobierno estatal se encuentra en una severa crisis y por lo tanto el personal administrativo cumple con la doble función empleando el respeto a los derechos humanos y el cumplimiento del deber del Cereso de Chetumal. ${ }^{31}$

Lo descrito en la entrevista muestra lo complejo y la magnitud del problema al que se enfrenta el proceso de implementación de la política pública, sobre todo por los costos de carácter social que conlleva. Al no implementar la LNEP, la población privada de su libertad carecerá de mecanismos o actividades de reinserción social que les permitan contar con herramientas en materia de trabajo, capacitación para el trabajo, cultura, deporte y salud. Por tal motivo, y desde la perspectiva teórica, quien diseña y dirige la implementación — el gobierno federal — debe considerar sus capacidades institucionales $\mathrm{y}$, sobre todo, la de los agentes que intervendrán. Esto quiere decir que se debe tener en consideración el análisis (para

30 Censo Nacional de Gobierno, Seguridad Pública y Sistema Penitenciario Estatales 2016. Resultados, México, Instituto Nacional de Estadística y Geografía (INEGI), 2017, p. 34.

31 Entrevista realizada el 10 de abril de 2017, Chetumal, Quintana Roo. El entrevistado solicitó que en el documento no apareciera su nombre, sino sólo el cargo. 
saber la viabilidad), el liderazgo (para conocer si es el momento oportuno para promover la política pública), la organización (el esfuerzo colectivo de los agentes involucrados) y la política (para conocer la cantidad de poder que tiene el principal impulsor). ${ }^{32}$

Esto se menciona porque las políticas públicas podrán tener objetivos precisos; sin embargo, si no se tiene un análisis o diagnóstico y si no se considera la viabilidad y el contexto político, no existe recurso que alcance para implementar políticas. Por tal motivo, existe una diferencia entre los Estados con sólidas estructuras políticas e instituciones regidas por la formalidad y los países con estructuras frágiles e instituciones arbitradas por la informalidad..$^{33}$ En este escenario, como en las demás políticas —incluida la reforma de los derechos humanos de 2011—, el federalismo ha jugado un papel relevante para la implementación. En el caso de México, el federalismo no necesariamente es un sistema construido bajo el precepto de la cooperación, sino un sistema vertical y de control, en el que los gobiernos estatales por mucho tiempo estuvieron destinados a acatar las disposiciones del centro.

Los cambios políticos ocurridos en las dos recientes décadas han significado autonomía y descentralización de las entidades federativas respecto al centro del país. Sin embargo, como señala Gibson, no se ha logrado modificar la manera en que se organiza y dirime la política a través de los territorios. ${ }^{34}$ Lo anterior implica la capacidad del principal agente de coordinar a las entidades federativas para que exista colaboración en la implementación de las políticas. No obstante, cabe señalar que la LNEP tiene mayor margen - a diferencia de otras políticas relacionadas a la política de seguridad- de implementación. Se instrumentará en un contexto acotado (espacial, territorial y poblacional), como lo son los centros penitenciarios, aunque esto no descarta que, aun cumpliendo con todos los objetivos de la política, los resultados, sobre todo en materia de reinserción social, no se cumplan.

\section{La retórica de la corresponsabilidad del individuo con el Estado}

El respeto de los derechos humanos como base de la reinserción social en los centros penitenciarios en México ha sido un avance para mejorar las

\footnotetext{
32 Franco Corzo, Julio, op. cit., pp. 114-118.

33 Medellín Torres, Pedro, op. cit., p. 8.

34 Gibson, E. L., "Control de límites: autoritarismo subnacional en países democráticos”, Desarrollo Económico, Buenos Aires, vol. 47, núm. 186, 2007, pp. 160-195.
} 
condiciones de los internos. Esto significa que, en cierta medida, se está cumpliendo con el precepto del artículo 18 constitucional. No obstante, al señalarse que se busca “... lograr la reinserción del sentenciado a la sociedad y procurar que no vuelva a delinquir...”, se dejan de lado dos aspectos importantes. El primero de ellos se relaciona con los centros penitenciarios y el contexto social en que se desenvolverá el liberado. Como bien señala Ramírez (citado por Oliveira), cómo alcanzar lo que la propia sociedad no supo dar en su tiempo a quienes están recluidos y que aspiran a reinsertarse en la comunidad. ${ }^{35}$

El segundo aspecto es el que se relaciona con las decisiones personales de cada individuo para llevar a cabo la acción de delinquir. Esto hace referencia a por qué un individuo que ha estado en un centro penitenciario - lo que en teoría implica recibir y tomar los programas de reinserción social-, una vez en libertad, decide reincidir en cometer actos ilícitos. Estos dos puntos conforman lo que en este apartado se denomina "la retórica gubernamental de la corresponsabilidad del individuo con el Estado", debido a que pueden generarse consecuencias no intencionadas si no se considera el contexto social e individual de la implementación de una política pública.

La retórica gubernamental mencionada parte de los planteamientos del Programa Nacional de Prevención Social de la Violencia y Delincuencia (PNPSVD) de la administración federal 2012-2018, el cual se diseñó con un enfoque de la seguridad ciudadana, que es una subcategoría de la seguridad humana. ${ }^{36}$ De esta manera, el PNPSVD busca privilegiar “... la participación ciudadana en la construcción de ambientes seguros a través de la prevención, además de entender la seguridad como un derecho humano que debe ser garantizado por el Estado pero que a su vez, debe ser coproducido por todos los actores sociales". ${ }^{37} \mathrm{Al}$ usar este enfoque se busca definir situa-

35 Oliveira de Barros Leal, C., "El sistema penitenciario desde la perspectiva de los derechos humanos: una visión de la realidad mexicana y de sus desafíos", Revista do Instituto Brasileiro de Direitos Humanos, Brasil, vol. 3, núm. 3, 2002, p. 3.

36 "Mientras que la seguridad humana aborda formas de vulnerabilidad que ponen en riesgo el goce de los derechos humanos en general, la seguridad ciudadana se refiere a tipos específicos de vulnerabilidad — aquéllos provocados por la violencia y el desposeimiento - y a la protección de los cimientos o raíces de los derechos fundamentales...". Casas-Zamora, Kevin, The Besieged Polis: Citizen Insecurity and Democracy in Latin America, Washington, Organization of American States, 2013, p. 2.

37 Secretaría de Gobernación, Bases del Programa Nacional para la Prevención Social..., cit. 
ciones ideales sobre lo que debería ser la ciudadanía, el orden, y, principalmente, que los ciudadanos deben estar en corresponsabilidad con el Estado.

Por tal motivo, fue necesario identificar los factores de riesgo; es decir, ambientes familiares deteriorados, embarazo temprano, desempleo, pobreza, deserción escolar, marginación, entre otras. ${ }^{38}$ Esta postura no es nueva y tiene sus defensores - por ejemplo, Briceño-León, Núñez, Rivera, Cerro y Meloni-, quienes señalan que estos factores son variables con gran peso al momento de explicar las causas de la violencia y delincuencia. ${ }^{39}$ Así, Arriagada y Godoy señalan que la conducta delictiva depende de la capacidad de los individuos para alcanzar las metas-éxitos de acuerdo con su entorno social y con la importancia asignada al éxito económico. ${ }^{40}$

En este mismo sentido, la interpretación social de la violencia, de acuerdo con Fuentes y Alavez, también se relaciona con el sistema de estructura social, el cual es violento por naturaleza, debido a que se expulsa de los beneficios sociales a un gran porcentaje de los miembros de la sociedad. ${ }^{41}$ Por tanto, desde esta perspectiva existiría una correlación importante entre pobreza y delincuencia. Sin embargo, según González, se insiste en la concepción del ser humano con conciencia y voluntad que puede y debe incidir en su entorno social y político. ${ }^{42}$ Empero, se debe tener presente que la sociedad no es un conjunto de intereses y conductas homogéneas, es decir, se debe considerar la arbitrariedad de elección del individuo.

Las decisiones de los seres humanos también son resultado de muchas pulsiones. Como señala Moriconi: "La realidad material condiciona, pero

\footnotetext{
38 Idem.

39 Briceño-León, R., "La violencia homicida en América Latina", América Latina Hoy, vol. 50, 2008, pp. 103-116; Núñez, J. et al., "Determinantes socioeconómicos y demográficos del crimen en Chile. Evidencia desde un panel de datos de las regiones chilenas", Estudios de Economía, vol. 30, núm. 1, 2003, pp. 55-85; Cerro, Ana María y Meloni, O., Análisis económico de las políticas de prevención y represión del delito en la Argentina, Córdoba (Argentina), Eudecor, 1999.
}

40 Arriagada, Irma y Godoy, L., Seguridad ciudadana y violencia en América Latina: diagnóstico y políticas en los años noventa, Santiago de Chile, CEPAL, División de Desarrollo Social, 1999, pp. 7 y 8.

41 Fuentes Romero, D. y Alavez Torres, J., "Consideraciones básicas sobre la definición de una teoría de violencia”, en Fuentes Romero, David (coord.), Violencia urbana y conflicto social. Hacia una interpretación de carácter regional y local fronteriza. El caso de Tijuana, Baja California (1999-2006), México, Universidad Autónoma de Baja California, 2010, pp. 26 y 27.

42 González, P., Seguridad ciudadana, Guatemala, Facultad Latinoamericana de Ciencias Sociales-Guatemala, 2003, pp. 17 y 18. 
no determina el mundo anímico de los individuos y los grupos". ${ }^{43}$ En el colectivo social, el Estado es el encargado de velar por la paz y el orden. Lo anterior no significa que no existan individuos que tengan intereses opuestos a la voluntad general. Pero ¿qué conduce a que un individuo transgreda las reglas formales? Como se señaló, el individuo está conformado por una serie de pulsiones y decisiones racionales influidas por el contexto social en el que se desarrolla. Estos contextos aludidos generalmente se caracterizan por la precariedad del empleo, la inequidad y el contexto de un crecimiento económico fundado en el consumo que deriva en las motivaciones e impulsos que conllevan a los "delitos aspiracionales". ${ }^{44}$

No obstante, como plantea Elster, muchos de esos impulsos deben mantenerse a raya por el daño acumulativo que pueden infligir si no se les controla - es necesario un contrapeso- Sin embargo, como afirma el autor, para estos individuos, en general, lo que está en juego pocas veces es tan grave como para considerar las consecuencias de su comportamiento. ${ }^{45}$ Para este tipo de individuos, los costos de estar dentro de una colectividad pueden ser más altos que la rentabilidad que les otorga el estar fuera de las reglas impuestas por el Estado. Esto no quiere decir que renuncien a los beneficios de ser ciudadanos — por ejemplo, el respeto a sus derechos humanos-, aunque no deseen cumplir con sus obligaciones como miembros de éste.

De lo expuesto, Elster señala que es posible que, de haber más cosas en juego, el individuo abandonaría su propósito; pero debido a que la situación no se plantea - porque no hay un contrapeso ante su decisión-, no se puede decir con certeza si se está simplemente ante una solución que no tiene otras opciones o ante la decisión de tomar el camino del menor esfuerzo. ${ }^{46}$ De esta manera, la dependencia del camino elegido permite que, una vez

43 Moriconi Bezerra, M., "Víctimas, cómplices e indiferentes: la retórica como replanteo de las políticas de seguridad y (educación) ciudadana", Foro Internacional, México, vol. 51, núm. 1, 2011, pp. 137 y 138.

44 El Informe nombra "delito aspiracional" a aquellos que se presentan en sociedades donde hay demanda de bienes de consumo, como productos eléctricos, electrónicos, celulares, Internet y automóviles, y, si el individuo no logra adquirirlos queda excluido de la integración social. Por tanto, el delito es la única opción para alcanzarlos. Véase PNUD, Informe Regional de Desarrollo Humano 2013-2014. Seguridad ciudadana con rostro humano: diagnóstico y propuestas para América Latina, Programa de las Naciones Unidas para el Desarrollo, 2013, p. 15.

45 Elster, J., La explicación del comportamiento social. Más tuercas y tornillos para las ciencias sociales, Barcelona, Gedisa, 2010, pp. 99-102.

46 Ibidem, pp. 102-110. 
decidida la acción a tomar, el individuo busque la manera de justificar sus actos - aludiendo a su condición social o de factores de riesgo-, para que sus razones sean decisivamente más fuertes.

En este punto es donde en la implementación de una política pública como la LNEP se debe considerar la "fragmentación institucional" y la "retórica gubernamental de la corresponsabilidad del individuo con el Estado" como parte de las consecuencias no intencionadas que se pueden generar si no se toma en cuenta la fortaleza institucional del Estado. Lo anterior se menciona porque los programas de reinserción social con base en los derechos humanos no son algo reciente. Por ejemplo, Morales et al. mencionan que el Proyecto Greenlight, implementado por el Instituto Vera de Justicia (Vera Justice Institute), en conjunto con el Departamento de Servicios Penitenciarios de Nueva York, consideró todas las aristas de la reinserción social, pero los resultados no fueron positivos. ${ }^{47}$

Esto llevó a considerar que, aun tomando todas las medidas posibles, existe la posibilidad de que la intervención no sea efectiva. ${ }^{48}$ Lo anterior se debió a que los programas de reinserción con base en los derechos humanos no consideran o no pueden controlar la arbitrariedad y la capacidad de decisión de los individuos. Sin embargo, es importante señalar que el éxito de los programas es sistémico y que depende en gran medida de la fortaleza y control institucional de los Estados para implementar las políticas públicas, convergiendo con todos los agentes involucrados.

Lo expuesto es señalado por Morales et al., quienes en su estudio citan que en los casos de Inglaterra y Gales la reinserción social ha sido un proceso de largo plazo, el cual ha requerido la participación del Poder Judicial; los sectores de gobierno; los ministerios del Trabajo, Salud y Vivienda; el sector privado, y la sociedad. ${ }^{49}$ Por tal motivo, y ante la evidencia, es inevitable aceptar que existe una paradoja entre el ideal de orden y paz social que buscan las políticas públicas y la complejidad que representan las sociedades. No obstante, en la medida que exista un Estado robusto en la contención de los impulsos y decisiones de los individuos para transgredir el orden social, habrá menos incentivos por parte de éstos para romper las reglas.

47 Morales P., A. M. et al., Reinserción social y laboral de infractores de ley. Estudio comparado de la evidencia, Santiago, Fundación Paz Ciudadana, 2015, pp. 11-15.

48 Ibidem, p. 15.

49 Idem. 


\section{CONCLUSIONES}

En el documento se analizó, desde una revisión normativa y desde la base teórica de las políticas públicas, los retos a los que se enfrenta la LNEP. Se reconoce que, como todo proceso implementación, la política pública puede quedar únicamente en un ordenamiento legal vanguardista si no se consideran las variables necesarias. Lo anterior se alude debido al número de agentes que intervienen en la implementación y también a las capacidades institucionales de los principales impulsores de la política, es decir, el gobierno federal. Esto se menciona porque se requiere del análisis, el liderazgo, la organización y, por supuesto, el principal factor: el político. Se hace hincapié en el factor político, porque la LNEP involucra a los gobiernos estatales en un esfuerzo presupuestal para instrumentar medidas de infraestructura penitenciaria, programas de capacitación de personal y de contratación de personal. En este punto, y como se señaló, es donde se encuentra otro de los grandes retos de la política pública.

No es únicamente trabajar en los problemas conocidos por diversos actores o agencias preocupados por el tema de las cárceles y la reinserción social de las personas privadas de su libertad, sino también la discrecionalidad con la que se han manejado los gobiernos estatales y las autoridades penitenciarias locales. Uno de ellos es la disponibilidad de información, la falta de conformación de los consejos técnicos y el poco compromiso de éstos por dar seguimiento a los programas de reinserción social. Como se explicó, el caso del Cereso en Chetumal, Quintana Roo, es muestra de lo que pasa en diversos estados del país.

La tarea de hacer converger a los gobiernos estatales para implementar políticas públicas es una labor de negociación y voluntad política, pero también una prueba de control territorial e institucional del Estado. En otras palabras, es la capacidad del gobierno para asegurar que el nuevo ordenamiento será conocido, aceptado y puesto en práctica por los que participan en su proceso. Este fenómeno que se presenta en la implementación de las políticas se debe en gran parte a lo que en el texto se denominó "fragmentación institucional", que conjuga con la falta de institucionalización del orden. Lo anterior también se relaciona con el poco interés que existe por parte de la sociedad que los reclusos en los centros penitenciarios sean reinsertados a la sociedad. Esto va más allá de que exista una preocupación por la inseguridad y los índices de criminalidad en el país, 
y quizá esté más relacionado con los valores y creencias arraigados en el imaginario colectivo sobre lo que la cárcel y el castigo han representado históricamente - análisis que está fuera del alcance del presente documento- .

Por tal motivo, es necesario establecer mecanismos para asegurar el cumplimiento de la LNEP por parte de las entidades federativas. En este apartado se proponen tres:

1) Es necesario que ante los avances de la implementación se tenga una respuesta por parte del Estado, sobre todo si éstos no son significativos. Se deben firmar convenios de colaboración entre las entidades federativas y el gobierno federal para estipular los plazos de cumplimiento. Asimismo, se deben establecer las sanciones a las que se verán sometidas las entidades federativas ante el incumplimiento. Uno de éstas podría ser que la SHCP recorte las participaciones federales en materia de seguridad a las entidades federativas que no tengan avances de acuerdo con lo planeado.

2) Otra de las medidas sería otorgar mayores facultades al OADPRS, para que los centros penitenciarios bajo el control de los gobiernos estatales mejoren la rendición de cuentas ante la Federación.

3) Por último, y buscando crear una mayor conciencia sobre la importancia de la reinserción social de los internos en los centros penitenciarios, es necesario la creación de un consejo ciudadano integrado por miembros de la sociedad civil, académicos e iniciativa privada. La importancia de esto se encuentra en dar seguimiento al proceso de reinserción social de los reclusos que sean liberados y den testimonio de su reincorporación a la sociedad.

Las propuestas anteriores no deben confundirse con la retórica gubernamental de que todos los individuos están en correspondencia con el Estado, debido a que parece ser la trampa en la que se suele caer al momento de tratar el tema del respeto de los derechos y la reinserción social de los reclusos. Así, el Estado como el garante del orden y la paz y, sobre todo, los responsables del diseño de políticas públicas deben considerar la arbitrariedad de los individuos en la sociedad. Lo anterior implica entender la dualidad de que existen individuos para los cuales es rentable la vida en comunidad (respetando las reglas) y para quienes es todo lo contrario. Por tal motivo, el Estado es donde debe intervenir con el poder de coerción 
para garantizar la paz, el orden y la seguridad de la comunidad, porque en la medida en que se permite la fragmentación del orden social, se pierde la capacidad de instaurar el orden institucional de un Estado.

\section{BIBLIOGRAFÍA}

ArriagadA, Irma y Godoy, L., Seguridad ciudadana y violencia en América Latina: diagnóstico y políticas en los años noventa, Santiago de Chile, CEPAL, División de Desarrollo Social, 1999.

Auditoría SuPERIOR DE LA FEDERACIÓN, Auditoría de desempeño del sistema nacional penitenciario, México, Auditoría Superior de la Federación, 2016.

AYALA ESPINO, José, Instituciones y economía, una introducción al neoinstitucionalismo económico, México, Fondo de Cultura Económica, 2011. Bustamante, Jesús, "Tenía dos meses preso y se fuga hijo de El Azul; Sinaloa pide ayuda federal", Excélsior, Culiacán (Sinaloa), 2017, disponible en: http://www.excelsior.com.mx/nacional/2017/03/17/1152456 (fecha de consulta: 25 de julio de 2017).

BRICEÑO-LEÓn, R., "La violencia homicida en América Latina", América Latina Hoy, vol. 50, 2008.

CÁMARA DE DipUTADOs, El presupuesto público federal para la función seguridad pública, 2015-2016, México, Cámara de Diputados, LXIII Legislatura, 2016.

CASAs-Zamora, Kevin, The Besieged Polis: Citizen Insecurity and Democracy in Latin America, Washington, Organization of American States, 2013.

Censo Nacional de Gobierno, Seguridad Pública y Sistema Penitenciario Estatales 2016. Resultados, México, Instituto Nacional de Estadística y Geografía (INEGI), 2017.

CERro, Ana María y Meloni, O., Análisis económico de las políticas de prevención y represión del delito en la Argentina, Córdoba (Argentina), Eudecor, 1999.

COMisión NACIONAL DE SEguridad, Cuaderno mensual de información estadística penitenciaria nacional, México, Órgano Administrativo Desconcentrado Prevención y Readaptación Social, 2013. 
COMISIÓN NACIONAL DE SEGURIDAD, Cuaderno mensual de información estadística penitenciaria nacional, México, Órgano Administrativo Desconcentrado Prevención y Readaptación Social, 2016.

Consejo Nacional de Evaluación de la Política de Desarrollo Social, Informe de Evaluación de la Política de Desarrollo Social 2016. Resultados, México, Consejo Nacional de Evaluación de la Política de Desarrollo Social, 2016.

ELSTER, J., La explicación del comportamiento social. Más tuercas y tornillos para las ciencias sociales, Barcelona, Gedisa, 2010.

Encuesta Nacional de Victimización y Percepción sobre Seguridad Pública 2011. Resultados, México, Instituto Nacional de Estadística y Geografía, 2011.

Encuesta Nacional de Victimización y Percepción sobre Seguridad Pública 2016. Resultados, México, Instituto Nacional de Estadística y Geografía, 2017.

"Escapan 141 presos del penal de Nuevo Laredo", La Jornada, México, 2010, disponible en: $h t t p: / / w w w . j o r n a d a . u n a m . m x / 2010 / 12 / 18 /$ politica/0 02n1pol (fecha de consulta: 20 de enero de 2018).

Franco Corzo, J., Diseño de políticas públicas, México, IEXE, 2013.

Fuentes Romero, D. y Alavez Torres, J., "Consideraciones básicas sobre la definición de una teoría de violencia”, en FUENTES ROMERO, David (coord.), Violencia urbana y conflicto social. Hacia una interpretación de carácter regional y local fronteriza. El caso de Tijuana, Baja California (1999-2006), México, Universidad Autónoma de Baja California, 2010.

GAlindo, Pedro, "En Durango también se fugan”, El Siglo de Torreón, Durango, 2015, disponible en: https://www.elsiglodedurango.com.mx/no ticia/603949.en-durango-tambien-se-fugan.html (fecha de consulta: 15 de enero de 2018).

GiBson, E. L., "Control de límites: autoritarismo subnacional en países democráticos”, Desarrollo Económico, Buenos Aires, vol. 47, núm. 186, 2007.

GonzÁlez, P., Seguridad ciudadana, Guatemala, Facultad Latinoamericana de Ciencias Sociales-Guatemala, 2003.

MEDEllín TORRES, Pedro, La politica de las politicas públicas: propuestas teórica y metodológica para el estudio de las políticas públicas en países de frágil institucionalidad, Santiago de Chile, CEPAL, 2004. 
MERINo, Mauricio, Politicas públicas. Ensayo sobre la intervención del Estado en la solución de problemas públicos, México, Centro de Investigación y Docencia Económica, 2016.

MORAlES P., A. M. et al., Reinserción social y laboral de infractores de ley. Estudio comparado de la evidencia, Santiago, Fundación Paz Ciudadana, 2015.

MORICONI BEZERRA, M., "Víctimas, cómplices e indiferentes: la retórica como replanteo de las políticas de seguridad y (educación) ciudadana", Foro Internacional, México, vol. 51, núm. 1, 2011.

Muedano, Marcos, "Registran cárceles déficit de custodios", El Universal, México, 2012, disponible en: http://www.eluniversal.com.mx/prime $\mathrm{ra} / 40382 . \mathrm{html}$ (fecha de consulta: 10 de enero de 2018).

“«Narcoreventón» del cártel Jalisco... en «su presidio»", Milenio, México, 2017, disponible en: $h t t p: / / w w w . m i l e n i o . c o m / p o l i c i a / n a r c o-r e v e n t o n-f i e s$ ta-cartel_jalisco-presidio-penal-puente_grande-don_chelo-milenio 0_953304665.html (fecha de consulta: 15 de enero de 2018).

NORTH, Douglas, Instituciones, cambio institucional y desempeño económico, México, Fondo de Cultura Económica, 1993.

NúÑEZ, J. et al., "Determinantes socioeconómicos y demográficos del crimen en Chile. Evidencia desde un panel de datos de las regiones chilenas", Estudios de Economía, vol. 30, núm. 1, 2003.

Oliveira DE BARros LEAL, C., "El sistema penitenciario desde la perspectiva de los derechos humanos: una visión de la realidad mexicana y de sus desafíos", Revista do Instituto Brasileiro de Direitos Humanos, Brasil, vol. 3, núm. 3, 2002.

PASQUino, Gianfranco, Nuevo curso de ciencia política, México, Fondo de Cultura Económica, 2011.

PATIÑO, Dainzú, "Entidades reducen su participación en la recaudación de impuestos", El Financiero, México, 2016, disponible en: http://www.el financiero.com.mx/economia/estados-reducen-su-participacion-en-larecaudacion-de-impuestos.html (fecha de consulta: 2 de marzo de 2018).

PÉREZ SÁnCHEZ, Margarita, "El estudio de las políticas públicas", en PÉREZ SÁNCHEZ, Margarita (ed.), Análisis de politicas públicas, Universidad de Granada, 2005.

PNUD, Informe Regional de Desarrollo Humano 2013-2014. Seguridad ciudadana con rostro humano: diagnóstico y propuestas para América Latina, Programa de las Naciones Unidas para el Desarrollo, 2013. 
PRESIDENCIA DE LA REPÚBLICA, "Reforma constitucional en materia de derechos humanos", disponible en: http://calderon.presidencia.gob.mx/ 2011/06/promulgacion-de-la-reforma-constitucional-en-materia-de-de rechos-humanos (fecha de consulta: 20 de mayo de 2017).

REAL DATO, J., “Actores, ideas e instituciones en las políticas públicas”, en PÉREZ SÁNCHEZ, Margarita (ed.), Análisis de politicas públicas, Universidad de Granada, 2005.

ROBLES DE LA RoSA, Leticia y RoSAS, Tania, "Sin dinero para nueva ley penal; austeridad posterga su aplicación”, Excélsior, México, 2017, disponible en: http://www.excelsior.com.mx/nacional/2017/05/16/1163716 (fecha de consulta: 5 de febrero de 2018).

SECRETARÍA De Gobernación, Bases del Programa Nacional para la Prevención Social de la Violencia y Delincuencia e Instalación de la Comisión Intersecretarial, México, Secretaría de Gobernación, 2013.

SECRETARÍA DE Gobernación, ¿Qué beneficios trae la Ley Nacional de Ejecución Penal?, 2016, disponible en: http://www.gob.mx/segob/articu los/que-beneficios-trae-la-ley-nacional-de-ejecucion-penal (fecha de consulta: 29 de mayo de 2017). 